Skin

Appendage

Disorders
Skin Appendage Disord 2017;3:156-160

DOI: 10.1159/000468991
Received: February 21, 2017

Accepted: March 7, 2017

Published online: April 22, 2017

\title{
Unsuccessful Treatment of Alopecia Areata with Simvastatin/Ezetimibe: Experience in 12 Patients
}

\author{
Mabe Freitas Gouveia ${ }^{a}$ Ralph M. Trüeb ${ }^{b}$ \\ a Department of Dermatology, Núcleo de Ensino Superior, São Paulo, Brazil; ${ }^{b}$ Center for Dermatology and \\ Hair Diseases Professor Trüeb, Wallisellen, Switzerland
}

\section{Keywords}

Alopecia areata $\cdot$ Simvastatin/ezetimibe $\cdot$ Myopathy

\begin{abstract}
Background/Aims: Alopecia areata is a common immunemediated hair condition with limited treatment options and success rates. There is evidence that statins, which are used for reducing atherogenesis and cardiovascular disease, have immunomodulatory activities and therefore may also be used for treatment of selected dermatologic conditions, including alopecia areata. Among treatments evaluated for alopecia areata, oral simvastatin/ezetimibe therapy is currently under the scrutiny of expert opinion. Methods: Prospective observational study of the efficacy and tolerability of simvastatin/ezetimibe $40 / 10 \mathrm{mg}$ (Inegy; MSD Merck Sharp \& Dohme AG, Lucerne, Switzerland) over a treatment period of 6 months in alopecia totalis, universalis, multipatch involvement of the scalp $>30 \%$, ophiasis, or diffuse alopecia areata. Results: Of the 12 patients included in the study, $67 \%$ had no hair regrowth, $24 \%$ transient diffuse or patchy hair regrowth, and $24 \%$ patchy regrowth of pigmented hair which was not considered cosmetically satisfactory. Adverse effects were observed in
\end{abstract}

\section{KARGER}

() 2017 S. Karger AG, Basel

E-Mail karger@karger.com

www.karger.com/sad
$24 \%$ of patients, who reported myalgia. One patient showed elevation of creatine phosphokinase. Conclusion: Simvastatin/ezetimibe is not effective for treatment of alopecia areata, at least in severe and/or cases refractory to other treatments, either as monotherapy or as adjuvant. Ultimately, in choosing such a treatment with questionable benefit, one must take the risk of serious adverse effects into careful consideration.

(c) 2017 S. Karger AG, Basel

\section{Introduction}

Alopecia areata is a common hair loss condition characterized by the acute onset of nonscarring alopecia in usually sharply defined areas. Some patients lose hair in only a small patch, while others may have more extensive involvement. Ophiasis is characterized by the loss of hair in the shape of a wave at the circumference of the head, alopecia totalis is the loss of all scalp hair, and alopecia universalis is the loss of all scalp and body hair. The latter are characterized by a poorer prognosis regarding both spontaneous remission and response to treatment. As a general rule, the progress of alopecia areata in an indi- 


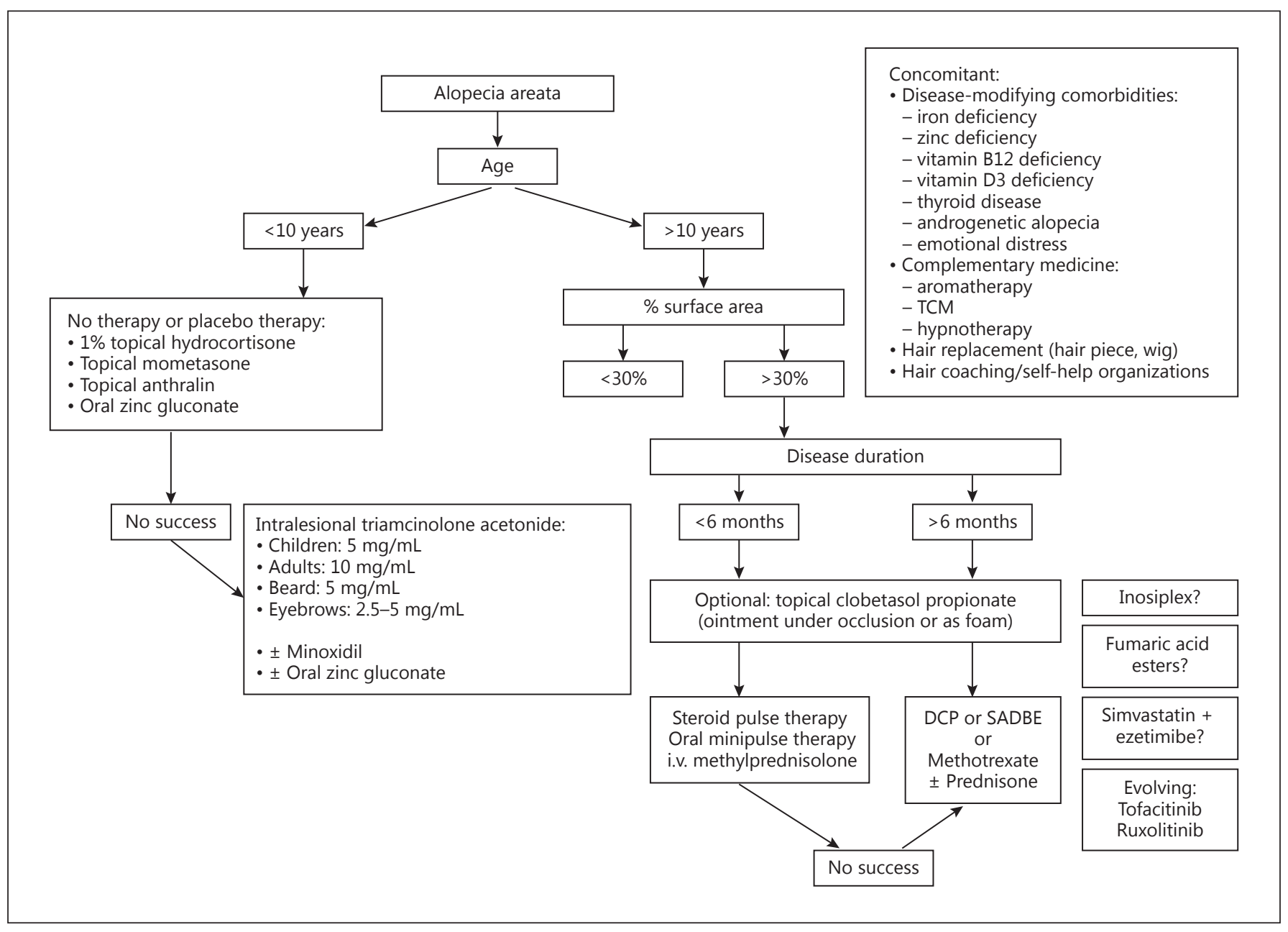

Fig. 1. Algorithm for the treatment of alopecia areata [4]. DCP, diphenylcyclopropenone; SADBE, squaric acid dibutylester.

vidual patient is unpredictable, though a large surface area, a long disease duration, and associated nail abnormalities have been connected with a poorer prognosis [1].

Alopecia areata represents an organ-specific autoimmune disease of the hair follicle with a T-cell mediated assault on the follicle on the level of the bulb, involving both innate and adaptive immunity [2].

A meta-analysis of published trials on treatment of alopecia areata states that only few treatments have been well evaluated in randomized trials [3]. Most trials have been reported poorly and are so small that any important clinical benefits are inconclusive. Delamere et al. [3] concluded that considering the possibility of spontaneous remission, especially for those in the early stages of disease, the options of not being treated or, depending on individual preference, of wearing a wig may be alternative ways of dealing with the condition.

Simvastatin/Ezetimibe in Alopecia Areata
Nevertheless, depending on patient age, surface area, and disease duration, an empiric treatment algorithm can be designed with total remission rates between 20 and $90 \%$ conditional on disease extent, duration, and choice of treatment, with corticosteroids and topical immunotherapy remaining the mainstay of therapy (Fig. 1) [4]. In general, any treatment chosen should fulfil the following criteria: remission rates superior to the spontaneous remission rates of alopecia areata, proof of efficacy in halfside treatment of alopecia totalis or universalis, and a good safety profile with minimal toxicity.

Among treatments for alopecia areata evaluated in the past (isoprinosine [5], fumaric acid esters [6], and methotrexate $[7,8]$ ) and in the present (the JAK inhibitors tofactinib [9] and ruxolitinib [10]), oral simvastatin/ezetimibe therapy is currently under the scrutiny of expert opinion [11-13]. 
Table 1. Characteristics of the included patients

\begin{tabular}{|c|c|c|c|c|c|c|c|}
\hline $\begin{array}{l}\text { Patient } \\
\text { No. }\end{array}$ & $\begin{array}{l}\text { Age, } \\
\text { years }\end{array}$ & Sex & $\begin{array}{l}\text { Severity/ } \\
\text { disease associations }\end{array}$ & $\begin{array}{l}\text { Duration, } \\
\text { years }\end{array}$ & Previous/ongoing treatments & Outcome & $\begin{array}{l}\text { Adverse } \\
\text { effects }\end{array}$ \\
\hline 1 & 32 & $\mathrm{~F}$ & $\mathrm{MPA}>30 \%$ & 5 & $\begin{array}{l}\text { Oral betamethasone minipulse therapy, topical and } \\
\text { intralesional corticosteroids, topical minoxidil, } \\
\text { vitamin D } \\
\text { Intralesional triamcinolone acetonide }\end{array}$ & $\begin{array}{l}\text { Transient diffuse hair } \\
\text { regrowth with total hair } \\
\text { loss in } 1 \text { month }\end{array}$ & $\begin{array}{l}\text { Myalgia } \\
\text { (normal } \\
\text { CPK) }\end{array}$ \\
\hline 2 & 59 & M & $\mathrm{MPA}>30 \%$ & 5 & $\begin{array}{l}\text { Oral betamethasone minipulse therapy, topical } \\
\text { and intralesional corticosteroids, vitamin D } \\
\text { Intralesional triamcinolone acetonide, } \\
\text { oral fexofenadine, vitamin D }\end{array}$ & $\begin{array}{l}\text { Transient diffuse hair } \\
\text { regrowth with total hair } \\
\text { loss in } 1 \text { month }\end{array}$ & None \\
\hline 3 & 49 & $\mathrm{~F}$ & $\begin{array}{l}\text { OT } \\
\text { vitamin D deficiency }\end{array}$ & 36 & $\begin{array}{l}\text { Excimer laser, topical and intralesional corticosteroids, } \\
\text { topical immunotherapy with DCP } \\
\text { DCP, vitamin D }\end{array}$ & No regrowth & None \\
\hline 4 & 25 & $\mathrm{~F}$ & $\begin{array}{l}\text { MPA }>70 \% \\
\text { Atopic disease }\end{array}$ & 15 & $\begin{array}{l}\text { Topical and intralesional corticosteroids, oral zinc, } \\
\text { vitamin D, low level laser therapy (LLLT) } \\
\text { DCP, vitamin D }\end{array}$ & No regrowth & None \\
\hline 5 & 63 & $\mathrm{~F}$ & $\begin{array}{l}\text { DA } \\
\text { Atopic disease }\end{array}$ & 6 & $\begin{array}{l}\text { Topical and intralesional corticosteroids, vitamin D } \\
\text { Compound of } 5 \% \text { minoxidil and } 0.2 \% \text { triamcinolone } \\
\text { acetonide, vitamin D }\end{array}$ & No regrowth & $\begin{array}{l}\text { Myalgia } \\
\text { Mild } \\
\text { elevation of } \\
\text { CPK }\end{array}$ \\
\hline 6 & 40 & $\mathrm{~F}$ & MPA > $30 \%$ & 6 & $\begin{array}{l}\text { Topical and intralesional corticosteroids, DCP } \\
\text { MTX and oral prednisolone, vitamin D }\end{array}$ & No regrowth & None \\
\hline 7 & 28 & $\mathrm{~F}$ & $\mathrm{AU}$ & 4 & $\begin{array}{l}\text { Topical and intralesional corticosteroids, DCP } \\
\text { MTX and oral prednisolone, vitamin D }\end{array}$ & No regrowth & None \\
\hline 8 & 32 & M & $\begin{array}{l}\text { AU } \\
\text { Vitamin D deficiency }\end{array}$ & 14 & $\begin{array}{l}\text { Topical corticosteroids, vitamin } \mathrm{D} \text {, compound of } 5 \% \\
\text { minoxidil and } 0.2 \% \text { triamcinolone acetonide, } \\
\text { oral finasteride } \\
\text { MTX and oral prednisolone, oral finasteride }\end{array}$ & No regrowth & None \\
\hline 9 & 41 & $\mathrm{~F}$ & $\begin{array}{l}\text { AU } \\
\text { Atopic disease }\end{array}$ & 5 & $\begin{array}{l}\text { Topical and intralesional corticosteroids, oral zinc } \\
\text { Topical clobetasol, oral zinc }\end{array}$ & No regrowth & None \\
\hline 10 & 33 & $\mathrm{~F}$ & OT & $>5$ & $\begin{array}{l}\text { Intravenous methylprednisolone pulse therapy, DCP, } \\
\text { vitamin D } \\
\text { Topical clobetasol, hypnotherapy }\end{array}$ & No regrowth & None \\
\hline 11 & 37 & $\mathrm{~F}$ & $\mathrm{AU}$ & 1 & $\begin{array}{l}\text { Intravenous methylprednisolone pulse therapy, DCP, } \\
\text { compound of topical minoxidil and corticosteroid } \\
\text { Topical clobetasol, vitamin D, oral zinc }\end{array}$ & $\begin{array}{l}\text { Patchy regrowth of } \\
\text { pigmented hair }<20\end{array}$ & None \\
\hline 12 & 33 & M & $\begin{array}{l}\text { AT } \\
\text { Vitamin D deficiency }\end{array}$ & 3 & $\begin{array}{l}\text { Topical and intralesional corticosteroids } \\
\text { DCP, vitamin D }\end{array}$ & $\begin{array}{l}\text { Patchy regrowth of } \\
\text { pigmented hair }<20\end{array}$ & None \\
\hline
\end{tabular}

AT, alopecia areata totalis; AU, alopecia areata universalis; MPA, multiple patches areata; OT, ophiasis type areata; DA, diffuse alopecia areata; DCP, diphenylcyclopropenone; MTX, methotrexate; CPK; creatine phosphokinase.

\section{Patients and Methods}

After having acknowledged the report of Lattouf et al. [11] on the efficacy of simvastatin/ezetimibe, we offered the respective therapy off label to patients with alopecia areata who had previously undergone treatment without satisfying results.

A prospective observational study was performed over a 6-month period in 12 patients older than 18 years, with alopecia totalis, universalis, multipatch involvement of the scalp $>30 \%$, ophiasis, or diffuse alopecia areata. After receiving their informed consent, patients were enrolled in the study.

Simvastatin/ezetimibe 40/10 mg (Inegy; MSD Merck Sharp \& Dohme AG, Lucerne, Switzerland) once daily was added to the ongoing treatment, and patients were visited every 6 weeks for assessment of adverse effects of the drug and blood tests (lipids profile, creatine phosphokinase [CPK], vitamin D3). Global photography was performed at baseline, at 3 months, and at 6 months. 


\section{Results}

The age of the included patients ( 9 females, 3 males) ranged from 25 to 63 years (mean: 42 years). Four of 12 (33\%) patients had alopecia areata universalis, $1(8 \%)$ alopecia areata totalis, $4(33 \%)$ multipatch areata (3 patients $>30 \%, 1$ patient $>70 \%), 2$ (17\%) ophiasis, and 1 (8\%) diffuse alopecia areata. In the majority of patients ( 9 of 12), disease duration exceeded 5 years. Three of $12(25 \%)$ patients had associated atopic disease, and 3 of 9 (33\%) patients in which vitamin $D$ levels were available at baseline had a deficiency of vitamin D3. Previous and ongoing treatments are summarized in Table 1.

At the end of the 6-month period, all patients (100\%) completed the study. Eight of 12 (67\%) patients had no hair regrowth, 2 (24\%) patients had a transient diffuse or patchy hair regrowth followed by total hair loss in 1 month during the treatment period, and 2 (24\%) patients had a patchy regrowth of pigmented hair $(<20 \%)$, which was not considered cosmetically satisfactory.

Adverse effects were observed in $2(24 \%)$ patients, who reported myalgia. However, they did not interrupt the treatment. One patient showed mild elevation of CPK.

\section{Discussion}

Namazi [14] originally proposed the use of statins for the treatment of a variety of dermatologic conditions characterized by ingress of activated leukocytes into the skin, including alopecia areata and vitiligo. The 3-hydroxy-3-methylglutaryl coenzyme A (HMG-CoA) reductase inhibitors (statins) atorvastatin, cerivastatin, fluvastatin, pravastatin, lovastatin, and simvastatin are currently used for reducing atherogenesis and cardiovascular morbidity, but there is increasing evidence that they also have immunomodulatory activities. Statins downregulate the expression of adhesion molecules, intercellular adhesion molecule-1 (ICAM-1), monocyte chemotactic protein-1 (MAC-1), and lymphocyte function-associated antigen-1 (LFA-1), on leukocytes and endothelial cells and, through binding to LFA-1, interfere with ICAM-1LFA-1 interaction, which is crucial for activation of lymphocytes by antigen-presenting cells, ingress of leukocytes into the inflammation sites, and immunologic cytotoxicity. Statins inhibit the inducible expression of major histocompatibility complex class II in several cell types, including macrophages, and downregulate the expression of T-helper 1 (Th1) chemokine receptors on T cells, leading further to inhibition of activation of lymphocytes

Simvastatin/Ezetimibe in Alopecia Areata and their infiltration into the inflammation sites. Statins block the induction of inducible nitric oxide synthase and the expression of several proinflammatory cytokines, such as tumor necrosis factor- $\alpha$ and interferon- $\gamma$, in macrophages and possess antioxidant effects. These agents inhibit the proliferation of immunocytes and the activation of natural killer cells.

Robins [15] was the first to observe hair regrowth following initiation of simvastatin and ezetimibe therapy in a patient with alopecia universalis. Subsequently, Ali and Martin [16] reported 2 patients with treatment-refractory alopecia that benefited significantly from treatment with simvastatin/ezetimibe in addition to the continuation of intralesional corticosteroid injections. Ultimately, Lattouf et al. [11] performed a prospective pilot study to evaluate the potential efficacy of simvastatin/ezetimibe (Vytorin; Merck and Co., Kenilworth, NJ, USA) 40/10 mg daily in patients with alopecia areata and reported a statistically significant association between being on therapy and stable remission of the disease. A total of 29 alopecia areata patients with $40-70 \%$ scalp involvement were enrolled: 19 patients completed 24 weeks of treatment, the remaining 10 patients were lost to follow-up. Fourteen of 19 patients were judged responders. Hair regrowth was evident after 16-24 weeks of treatment. Upon completion of the initial 24 weeks of treatment, the 14 responders were randomized into a group of 7 patients who continued treatment for an additional 24 weeks or into a group of 7 patients who stopped medication. In the former group, 5 of 7 patients continued with hair growth or had stable disease, while in the latter group, 5 of 7 patients relapsed. No side effects were observed.

Subsequently, Loi et al. [12] published their experience with simvastatin/ezetimibe treatment (Vytorin; Merck and Co.) $40 / 10 \mathrm{mg}$ daily in 20 patients with severe alopecia areata. Inclusion criteria included interruption of any local or systemic treatments at least 20 days before enrollment. At the end of the 6-month treatment period, 17 patients completed the study. A total of 14 of 17 patients had no hair regrowth, and 1 patient had patchy hair regrowth that was not considered cosmetically acceptable. The authors concluded that they did not obtain any result with simvastatin/ezetimibe in severe alopecia areata.

In reply, Lattouf et al. [13] argued that it is not completely surprising that statins should not be effective in patients with long-standing severe alopecia areata, since statins' immunological mechanism of action is more directed in preventing interferon- $\gamma$ signaling and lymphocyte activation, which represent a more important target in acute alopecia areata. Statins were allegedly shown to

Skin Appendage Disord 2017;3:156-160 159 
prevent alopecia areata in a mouse model, and a similar preventive effect has been reported in a mouse model of vitiligo [17]. In their personal experience, statins would be helpful in preventing relapses in patients who have had hair regrowth with other treatments, and they offer an adjuvant option for patients with active disease who show minimal progress on other treatments.

Despite the promising results of the initial pilot study [11], our findings regretfully are in line with Loi et al.'s [12] experience that simvastatin/ezetimibe is not effective for treatment of alopecia areata, at least in severe and/or cases refractory to other treatments, either as monotherapy or as adjuvant.

Moreover, 2 patients in our study developed myalgia, and 1 patient had elevated serum CPK levels. In choosing such a treatment with questionable benefit, one must take the respective advice on statin risk released by the US Food and Drug Administration in January 2014 into careful account: "They need to be taken with care and knowledge of their side effects." Among them, the most common complication is myopathy, ranging from benign myalgia to life-threatening rhabdomyolysis. Risk factors that increase this risk include: drug-drug interactions, especially with cytochrome P-450 3A4 inhibitors (including grapefruit juice), female gender, advanced age, and comorbidities, such as diabetes mellitus, hypothyroidism, and vitamin D deficiency [18], conditions that are not infrequently encountered in patients with alopecia areata.

Ultimately, considering the high rate of spontaneous remission of alopecia areata in small patches and early disease, the option of not being treated with simvastatin/ ezetimibe may be taken into consideration, while together with the experience in our additional patients with alopecia areata, the evidence is accumulating that simvastatin/ezetimibe is not helpful for severe and long-standing disease.

\section{Statement of Ethics}

Patients' informed consent was obtained.

\section{Disclosure Statement}

R.M.T. has no disclosures to report. This case report represents an integral part of M.F.G's traineeship in Dermato-Trichology at the Center for Dermatology and Hair Diseases Professor Trüeb.

\section{References}

1 Tosti A, Bellavista S, Iorizzo M: Alopecia areata: a long-term follow-up study of $191 \mathrm{pa}$ tients. J Am Acad Dermatol 2006;55:438441.

2 Petukhova L, Duvic M, Hordinsky M, Norris D, Price V, Shimomura Y, Kim H, Singh P, Lee A, Chen WV, Meyer KC, Paus R, Jahoda CA, Amos CI, Gregersen PK, Christiano AM: Genome-wide association study in alopecia areata implicates both innate and adaptive immunity. Nature 2010;466:113-117.

3 Delamere FM, Sladden MM, Dobbins HM, Leonardi-Bee J: Interventions for alopecia areata. Cochrane Database Syst Rev 2008; 16:CD004413.

4 Trüeb RM: The Difficult Hair Loss Patient. Guide to Successful Management of Alopecia and Related Conditions. Cham, Springer International Publishing AG Switzerland, 2015,

5 Georgala S, Katoulis AC, Befon A, Georgala K, Stavropoulos PG: Inosiplex for treatment of alopecia areata: a randomized placebo-controlled study. Acta Derm Venereol 2006;86: 422-424.

6 Venten I, Hess N, Hirschmüller A, Altmeyer $\mathrm{P}$, Brockmeyer N: Treatment of therapy-resistant alopecia areata with fumaric acid esters. Eur J Med Res 2006;11:300-305.
7 Joly P: The use of methotrexate alone or in combination with low doses of oral corticosteroids in the treatment of alopecia totalis or universalis. J Am Acad Dermatol 2006;55: 632-636.

8 Chartaux E, Joly P: Long-term follow-up of the efficacy of methotrexate alone or in combination with low doses of oral corticosteroids in the treatment of alopecia areata totalis or universalis. Ann Dermatol Venereol 2010;137:507-513.

9 Craiglow BG, King BA: Killing two birds with one stone: oral tofacitinib reverses alopecia areata universalis in a patient with plaque psoriasis. J Invest Dermatol 2014;134:29882990.

10 Xing L, Dai Z, Jabbari A, et al: Alopecia areata is driven by cytotoxic $\mathrm{T}$ lymphocytes and is reversed by JAK inhibition. Nat Med 2014;20: 1043-1049.

11 Lattouf C, Jimenez JJ, Tosti A, Miteva M, Wikramanayake TC, Kittles C, Herskovitz I, Handler MZ, Fabbrocini G, Schachner LA: Treatment of alopecia areata with simvastatin/ezetimibe. J Am Acad Dermatol 2015; 72:359-361.

12 Loi C, Starace M, Piraccini BM: Alopecia areata (AA) and treatment with simvastatin/ ezetimibe: experience of 20 patients. J Am Acad Dermatol 2016;74:e99-e100.

13 Lattouf C, Schachner LA, Wikramanayake TC, Kittles C, Tosti A, Miteva M, Jimenez JJ, Herskovitz I, Handler MZ, Fabbrocini G: Reply: alopecia areata treatment with simvastatin/ ezetimibe. J Am Acad Dermatol 2016;74:e101.

14 Namazi MR: Statins: novel additions to the dermatologic arsenal? Exp Dermatol 2004:13: 337-339.

15 Robins DN: Case reports: alopecia universalis: hair growth following initiation of simvastatin and ezetimibe therapy. J Drugs Dermatol 2007;6:946-947.

16 Ali A, Martin JM 4th: Hair growth in patients alopecia areata totalis after treatment with simvastatin and ezetimibe. J Drugs Dermatol 2010;9:62-64

17 Agarwal P, Rashighi M, Essien KI, Richmond JM, Randall L, Pazoki-Toroudi H, Hunter CA, Harris JE: Simvastatin prevents and reverses depigmentation in a mouse model of vitiligo. J Invest Dermatol 2015;135:1080-1088.

18 Magni P, Macchi C, Morlotti B, Sirtori CR, Ruscica M: Risk identification and possible countermeasures for muscle adverse effects during statin therapy. Eur J Intern Med 2015; 26:82-88. 